\section{Gestão democrática e práticas de apoio institucional na Atenção Primária à Saúde no Distrito Federal, Brasil}

\author{
Democratic management and institutional support \\ in primary care in the Federal District, Brazil
}

\author{
Prácticas de gestión democrática y de apoyo \\ institucional en la atención primaria de \\ salud en el Distrito Federal, Brasil
}

Janaina Rodrigues Cardoso 1 Gustavo Nunes de Oliveira 1 Paula Giovana Furlan 2

\title{
Resumo
}

\begin{abstract}
A pesquisa foi realizada no âmbito do Sistema Único de Saúde (SUS) do Distrito Federal, Brasil, apostando-se na inserção do apoio institucional como dispositivo para ressignificar a compreensão dos processos de trabalho e de gestão da Atenção Primária. Nesse contexto, buscou-se cartografar as práticas de apoio na Atenção Primária à Saúde da Regional Administrativa do Recanto das Emas e correlacioná-las com as prioridades de saúde do Distrito Federal, mediante pesquisa-intervenção, sob referencial qualitativo, com métodos participativos e produção de narrativas coletivas. A experimentação do apoio propiciou: qualificação e alinhamento das ações institucionais com as prioridades da gestão; qualificação, humanização e melhoria dos processos de trabalho e da gestão; implantação de colegiados gestores; intervenção nas práticas cotidianas dos serviços da Atenção Primária. Conclui-se que as práticas de apoio podem aprimorar os processos de gestão democrática e contribuem para a qualificação da assistência.
\end{abstract}

Atenção Primária à Saúde; Integralidade em Saúde; Gestão em Saúde; Humanização da Assistência

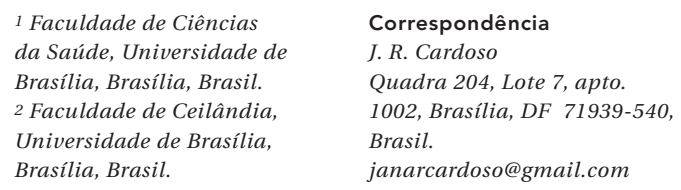

1 Faculdade de Ciências da Saúde, Universidade de Brasília, Brasília, Brasil. 2 Faculdade de Ceilândia, Universidade de Brasília, Brasília, Brasil. 


\section{Introdução}

A história das políticas públicas de saúde, em especial na Atenção Primária no Distrito Federal, Brasil, teve, como marcos importantes, os programas Saúde em Casa (1997-1998), Saúde da Família (1999-2003) e Família Saudável (2004-2006). Tais políticas tiveram, em comum, a focalização da oferta de um pacote de serviços de Atenção Primária às parcelas populacionais, em especial às de periferias urbanas. Em todo esse transcurso, dois modelos de Atenção Primária tiveram que conviver juntos, um baseado em unidades tradicionais não territorializadas e outro baseado na Estratégia Saúde da Família (ESF) 1.

De 2006 em diante, o Programa Família Saudável passou a ser denominado Estratégia Saúde da Família, e todas as ações da Atenção Primária coordenadas pela Diretoria de Atenção Primária.

Em agosto de 2010, foi criada a Subsecretaria de Atenção Primária em Saúde 2 encarregada da Reorganização da Atenção Primária pelo Governo do Distrito Federal, a partir da expansão e da qualificação da ESF.

O Governo do Distrito Federal, em 2012, elaborou o Plano Distrital de Saúde (2012-2015) 3 , equivalente aos Planos Estaduais de Saúde, com três grandes objetivos: (1) aumento da eficiência nas intervenções setoriais para a melhoria das condições de saúde da população; (2) aprimoramento dos processos de gestão no âmbito da Secretaria de Estado da Saúde (SES) e (3) adequação da infraestrutura em saúde às necessidades da população. Para cada um desses objetivos, foram estabelecidas diretrizes, dentre as quais a estruturação do atendimento em Atenção Primária com ênfase na ESF e a inovação das práticas de gestão do trabalho e da educação em saúde para a valorização e a qualificação das relações de trabalho dos profissionais da SES do Distrito Federal (SES-DF).

Não obstante os esforços da gestão da SES-DF para o fortalecimento da Atenção Primária, algumas experiências já acumuladas no Sistema Único de Saúde (SUS), como as dos Municípios de Vitória (Espírito Santo), vivenciadas por Cardoso 4 e Oliveira 5; de Campinas (São Paulo), por Campos 6; de São Paulo (São Paulo), por Andrade \& Castanheira 7; de Natal (Rio Grande do Norte), por Barros \& Dimenstein 8; de Capivari (São Paulo), por Arona 9; de Maringá (Paraná), por Moura \& Luzio 10 e Becchi et al. ${ }^{11}$; de Aracaju (Sergipe), por Vasconcelos \& Morschel 12; do Rio de Janeiro, por Barros et al. 13, demonstram que, além de unidades, equipes e equipamentos, o sistema de saúde pode ser ampliado e qualificado a partir da inserção da estratégia do apoio institucional e do apoio matricial nos processos de gestão e de atenção no SUS. Nesses casos citados, a estratégia do apoio demonstrou as funções de promover: ampliação na capacidade de análise e de intervenção das equipes de saúde e dos gestores de serviços de saúde; qualificação das intervenções de saúde na capacidade de gestão do cuidado; inserção de ferramentas de coordenação do cuidado e de governança clínica; indução de espaços colegiados como dispositivos para cogestão em saúde; ampliação da participação do usuário e sua corresponsabilização; conformação da clínica compartilhada entre os especialistas e clínicos da Atenção Primária; fortalecimento da Atenção Primária na consolidação das diretrizes da Política Nacional de Atenção Básica (PNAB) e mudanças no processo vertical da transmissão passiva do conhecimento, instituindo o apoiador como formador em processos de educação permanente inseridos no cotidiano do trabalho.

Conforme a PNAB, no Brasil, a ESF deve ser o contato preferencial dos usuários, a principal porta de entrada e o centro de comunicação de toda a Rede de Atenção à Saúde 14 . O SUS já possui acúmulos para enfrentar os desafios e seus problemas para a implementação da rede, e alguns dispositivos para o enfrentamento desses desafios foram desenvolvidos e sistematizados em 15: colegiado gestor, programa de formação em saúde do trabalhador e equipe de referência e de apoio matricial. Para agregar intensidade e qualidade a esses dispositivos, investe-se na inserção do apoio institucional e matricial como metodologia potente para ressignificar a compreensão dos processos de trabalho em saúde e gestão.

O apoio é um método de intervenção que expressa um modo de fazer em grupalidade, buscando-se redes de coletivos. Os apoiadores exercem a função de ampliar a capacidade de as pessoas lidarem com o poder, com a circulação de afetos e saber, ao mesmo tempo em que estão trabalhando, cumprindo tarefas. Sua potencialidade está na sua implicação, a partir da inserção no cotidiano de produção de saúde. O apoio matricial busca enfrentar a tendência à fragmentação da atenção à saúde oferecendo tanto retaguarda assistencial especializada quanto suporte técnico-pedagógico 5,16.

Para que o apoiador consiga realizar suas funções, é importante que existam espaços coletivos ou que esses espaços sejam criados ou reformulados com seu apoio. Esses espaços são arranjos para o trabalho cogestivo e participativo, criando condições para democratização das relações de trabalho e de produção, apostando na ampliação da autonomia dos sujeitos 16 . 
Os desafios e diretrizes da gestão do Governo do Distrito Federal, anteriormente apresentados para a implantação e implementação da Atenção Primária, justificaram e constituíram ponto de partida para a realização da pesquisa Cartografia do Apoio Institucional e Matricial no SUS do Distrito Federal: Áreas Prioritárias da Atenção e Gestão em Saúde e a Formação de Apoiadores na Atenção Primária em Saúde pelos professores e pesquisadores da Universidade de Brasília (UnB) e da Fundação Oswaldo Cruz (Fiocruz), os quais propuseram à SES a implementação do projeto de pesquisa, com método de pesquisa-intervenção participativa. Disparou-se daí a experimentação do apoio institucional para a formação de trabalhadores a partir de intervenção com o SUS local e regional, sustentada por escolhas metodológicas e posicionamentos éticos, estéticos e políticos acerca do entendimento do papel da universidade pública no desenvolvimento institucional do SUS regional 17 .

A partir de fevereiro de 2013, foram realizadas reuniões estratégicas de pactuação e delineamento do objeto de intervenção junto à Subsecretaria de Atenção Primária em Saúde, nas quais foram explicitados interesses em mudanças no modelo de gestão, almejando o estabelecimento de um contato direto da equipe do nível central com as regionais de saúde a partir da estratégia do apoio institucional. A partir de um diagnóstico situacional inicial, construído juntamente com os gestores da Subsecretaria de Atenção Primária em Saúde, identificou-se baixa capacidade dos gestores regionais e da gestão central na qualificação das práticas em saúde e uma fragmentação da relação institucional entre a subsecretaria e as regionais. Os gestores manifestaram interesse em iniciar uma intervenção nas regionais Gama e Recanto das Emas, devido à implantação da ESF e dos Núcleos de Apoio à Saúde da Família e a construção de um modelo de gestão participativo.

No presente estudo, a Regional de Saúde do Recanto das Emas foi nosso campo de pesquisa, uma vez que nela se constituiu o "campo de intervenção", espaço-tempo de encontro dos coletivos intervindos 18 , por ser uma regional que possui população estimada de 135 mil habitantes, com $84,1 \%$ da população dependente do SUS, não possui equipamento hospitalar público ou privado e que estava implantando mudanças do modelo de Atenção Primária tradicional para ESF 19.

Diante disso, assumimos, como atividade de pesquisa, a partir da experimentação do apoio na relação entre a universidade e o SUS, o objetivo de cartografar as práticas de apoio da Subsecretaria de Atenção Primária em Saúde e da
Diretoria Regional de Atenção Primária à Saúde (DIRAPS) do Recanto das Emas e correlacionálas com as prioridades da gestão do SUS no Distrito Federal.

\section{Caminho metodológico}

Este trabalho é uma pesquisa-intervenção, sob referencial qualitativo, que utiliza métodos participativos para a produção de dados. A estratégia do apoio institucional colocou, em relação, nove pesquisadores, 14 gestores e oito trabalhadores (Universidade, Governo, Estruturas de Estado, Território, Serviços, Grupos de Interesse) para a conformação do plano de intervenção, a partir do Método da Roda, de acordo com Campos 16.

O conceito de intervenção aqui colocado é derivado da Socioanálise e da Análise Institucional 20 , destacando-se que a potência interventiva é a alteração do estado de coisas, que é diretamente relacionada com a possibilidade das estratégias e táticas utilizadas pelos coletivos “intervindos" propiciarem a ação instituinte, de forma plena e continuada no interior das instituições, suas organizações e equipamentos 18 .

Nesse contexto, utilizamos, como método de pesquisa, a cartografia, que se "faz por pistas que orientam o percurso da pesquisa sempre considerando os efeitos do processo do pesquisador sobre o objeto da pesquisa, o pesquisador e seus resultados" 21 (p. 17).

Para fazer o plano interventivo precipitar os dados de pesquisa propriamente ditos, foi necessário constituir procedimentos coerentes com o referencial democrático de produção de conhecimento, de pesquisa participativa 22 , que permitissem um alto grau de coletivização da própria delimitação e interpretação dos achados de pesquisa a partir dos acontecimentos que emergiam do plano interventivo. As técnicas de investigação utilizadas desse modo foram: os grupos focais, as entrevistas individuais, os diários de campo de pesquisa e as memórias de encontros; que produziram narrativas coletivas que foram validadas no percurso da pesquisa.

Desde o primeiro encontro do grupo de pesquisa, na medida em que esse ia se articulando e incluindo os sujeitos no plano interventivo, a discussão metodológica em grupo, a composição de narrativas coletivas dos encontros e a análise das situações vivenciadas, registradas e validadas, em ciclos sucessivos de espaços coletivos, foram constituindo o material de pesquisa sob uma perspectiva coletiva e participativa 17. As narrativas, produzidas a partir das memórias de encontros e grupos focais, foram validadas em ciclos hermenêuticos, conforme proposto por 
Gadamer 23. Dessa forma, as categorias analíticas destacadas emergiram na intersecção entre os movimentos de narratividade, a partir dos acontecimentos do plano interventivo. Portanto, a cartografia das práticas de apoio se constituiu nesse mapeamento dos movimentos de mudança dos e nos sujeitos participantes, disparados pelos processos de apoio e expressos pelas categorias analíticas validadas coletivamente 17 .

Em abril de 2013, iniciou-se a conformação do desenho de intervenção do apoio com a construção de oito espaços coletivos (Tabela 1).

No período de abril de 2013 a dezembro de 2014, foram realizadas 77 rodas de apoio e quatro grupos focais, que produziram processos de formação e intervenção, de acordo com a Tabela 2, no Recanto das Emas, e duas entrevistas individuais.

Com esse arranjo, a intervenção não poderia ser olhada de forma isolada, com foco em um serviço, uma regional ou uma reunião, portanto, ficou configurada, no desenho, entre os diversos espaços coletivos intercessores 5,24, uma influência mútua, compondo o desenho cartográfico 17 (Figura 1).

Durante o mês de fevereiro de 2014, foram realizadas entrevistas com gestores da Subsecretaria de Atenção Primária em Saúde e da

Tabela 1

Tabela de constituição dos grupos de intervenção do apoio.

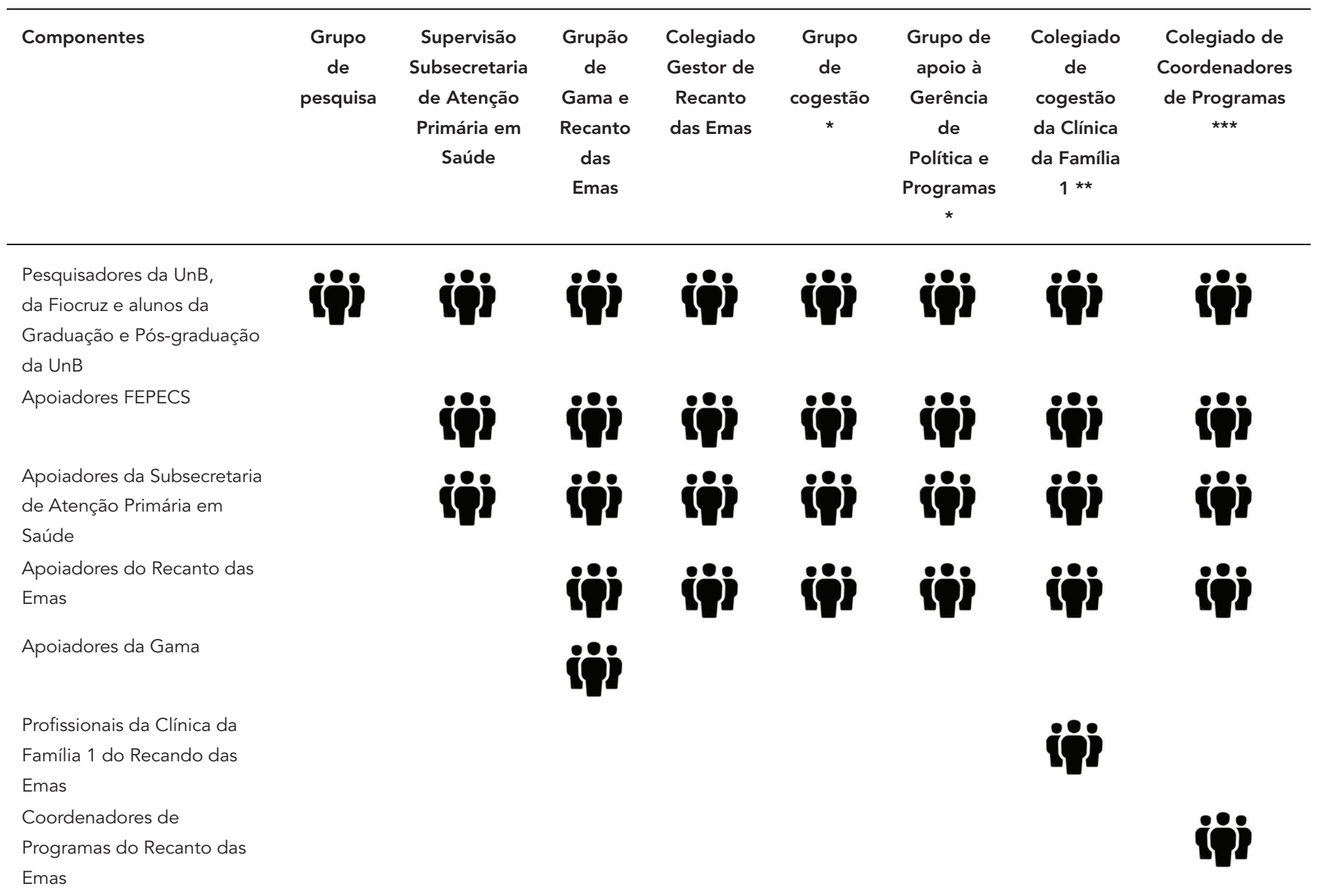

FEPECS: Fundação de Ensino e Pesquisa em Ciências da Saúde; Fiocruz: Fundação Oswaldo Cruz; UnB: Universidade de Brasília.

* Grupo criado a partir do Colegiado Gestor de Recanto das Emas;

** Grupo criado a partir do grupo de cogestão;

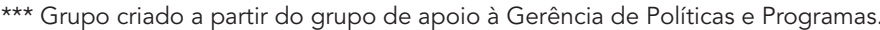


Tabela 2

Quantidades de encontros por grupos de intervenção do apoio.

\begin{tabular}{lcc}
\hline Espaços de intervenção do apoio & Quantidade de rodas de apoio \\
\hline Grupo de pesquisa & 13 & Quantidade de grupos focais \\
Supervisão Subsecretaria de Atenção Primária em Saúde & 5 & 18 \\
Grupão Gama e Recanto das Emas & 15 & - \\
Colegiado Gestor de Recanto das Emas & 4 & 3 \\
Grupo de cogestão & 3 \\
Grupo de apoio à Gerência de Políticas e Programas & 3 \\
Colegiado de cogestão da Clínica da Família 1 do Recanto das Emas & 16 \\
Colegiado de Coordenadores de Programas do Recanto das Emas & - \\
\hline
\end{tabular}

Figura 1

Diagrama de intervenção dos espaços coletivos.

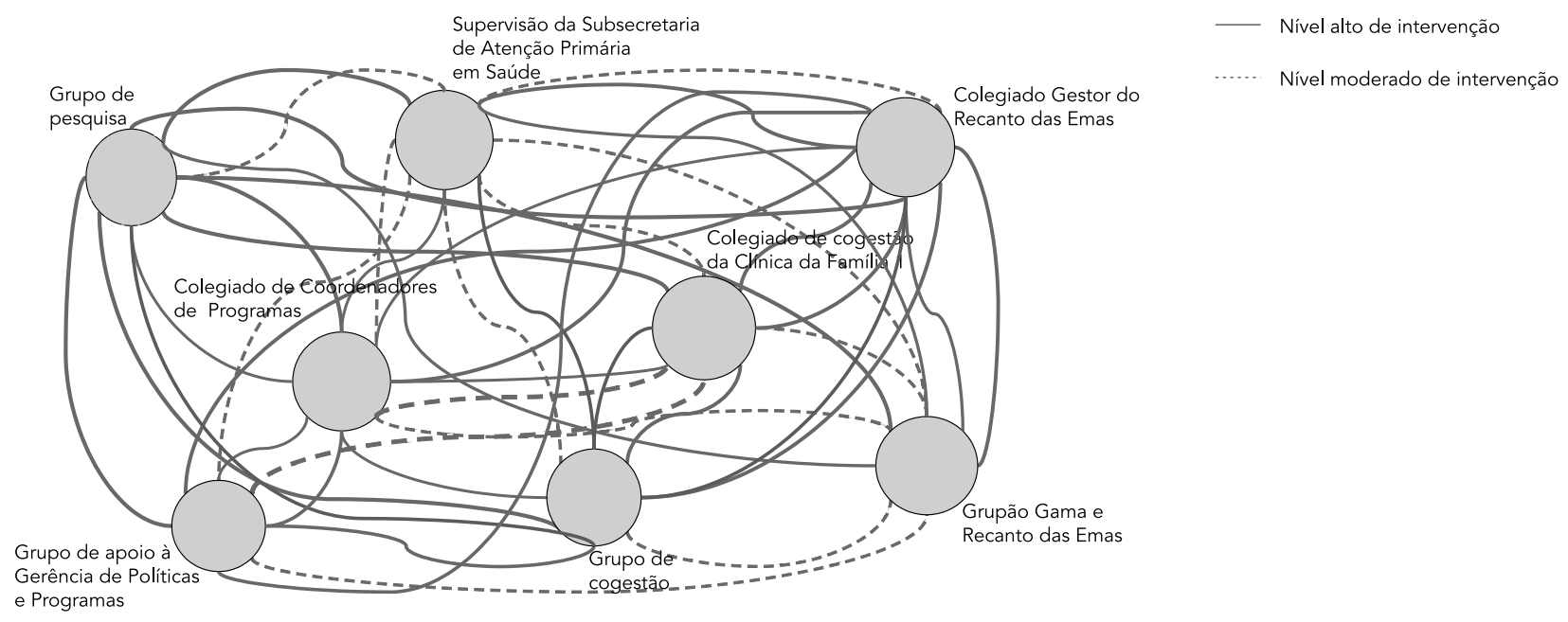

Coordenação Geral de Saúde do Recanto das Emas, com o objetivo de identificar as prioridades da gestão para a Atenção Primária e suas percepções sobre a contribuição do apoio para o alcance dessas prioridades.

Nos meses de maio e agosto de 2014 (Colegiado Gestor do Recanto das Emas) e de junho e setembro de 2014 (Colegiado dos Coordenadores de Programas), respectivamente, foram realizados dois ciclos de grupos focais narrativos. Nesses ciclos, as primeiras rodadas tiveram como objetivos analisar as prioridades da gestão regional para a Atenção Primária e a contribuição do apoio para o seu alcance, assim como os processos de apoio instituídos. As segundas rodadas foram realizadas três meses depois e foram divididas em dois momentos: o primeiro para apresentação da construção da narrativa para o grupo corrigi-la, discuti-la e validá-la, e o segundo para a atualização da narrativa e a rediscussão de alguns temas destacados pelo coletivo para o processo de análise e intervenção do apoio.

Esses encontros, grupos focais e entrevistas individuais, foram realizados mediante consentimento livre e esclarecido dos sujeitos e registrados em áudio e transcritos posteriormente. 
Durante a realização dos grupos focais, observadores captaram e registraram informações não-verbais expressas pelos participantes. Os pesquisadores elaboraram diários de campo que buscaram fazer rupturas e religações, encadeando acontecimentos, histórias e linhas argumentativas em um trabalho de interpretação em suas dimensões de análise e de construção 25,26,27. As narrativas foram construídas reunindo-se informações das transcrições, das anotações dos observadores e do diário de campo, construindo-se enredos próprios dos sujeitos de interesse. A leitura e a validação das narrativas fizeram emergir as categorias de análise e o desfecho interpretativo dos achados de pesquisa.

Diante do encerramento das atividades de pesquisa, foi realizada uma roda final de avaliação, em novembro de 2014, com a participação de todos os grupos de interesse para compartilhamento da análise das experiências vivenciadas e dos materiais de pesquisa produzidos. Esse espaço proporcionou entendimento e explicitação coletiva dos acúmulos produzidos durante o processo e dos resultados para os sujeitos e instituições envolvidas, em especial do papel da universidade pública no desenvolvimento institucional do SUS do Distrito Federal.

Esta pesquisa foi aprovada pelos Comitês de Ética em Pesquisa da Faculdade de Saúde da UnB (parecer no 191.003) e da Fundação de Ensino e Pesquisa em Ciências da Saúde - FEPECS/ SES-DF (parecer no 453.476).

\section{Resultados e discussão}

Na primeira roda de apoio, em abril de 2013, identificou-se a existência de um colegiado gestor que se reunia mensalmente. Essas reuniões seriam o espaço de intervenção do apoio, denominado Colegiado Gestor do Recanto das Emas, a partir da construção de relações de compromissos firmados entre as instituições e os sujeitos participantes do projeto.

"Nós estamos tentando construir uma gestão mais participativa. Temos um colegiado gestor, mas não temos um método que nos ajude a fazer com que esse espaço seja de cogestão, que nos ajude a mudar os nossos processos de trabalho. Não conseguimos implantar os colegiados nas unidades de saúde e hoje não conseguimos exercer o papel de gerentes. Os profissionais apresentam resistência para a implementação das ações e as veem com uma tarefa adicional e não compreendem que as ações propostas visam à melhoraria da atenção à saúde. Com a proposta do apoio, temos como expectativa aprender uma nova forma de gerenciar que nos ajude a promover a mudança do modelo de Atenção Primária tradicional para a ESF, de forma que os profissionais não entendam como sendo um movimento verticalizado e imposto, e sim horizontalizado e participativo" (narrativa Colegiado Gestor do Recanto das Emas).

Foram percebidas dificuldades no processo de gestão e a necessidade de entendimento sobre como os atores se percebem nesse processo, e, para isso, foi sugerido que cada gestor construísse um diário de campo, durante uma semana, para registro de suas atividades, com o objetivo de identificar se o seu trabalho era condizente ou não com o estabelecido para a sua função. Com isso, foi possível identificar que os gestores não tinham momentos para refletirem sobre o seu processo de trabalho, e isso vinha prejudicando o planejamento de suas atividades.

A segunda atividade realizada pelo Colegiado Gestor do Recanto das Emas foi a construção de um organograma "relacional", identificando as relações institucionais, pessoais e fluxos inventados para gestão cotidiana, contrapondo o engessamento de um organograma verticalizado e que distancia as funções de gestor e trabalhador. A partir disso, o grupo propôs a realização de uma oficina para identificação de problemas (relacionados na Figura 2) e respectivos eixos de intervenção: a criação de espaços compartilhados de gestão e cogestão nas unidades básicas de saúde; e a reorganização das atribuições e competências dos coordenadores de programas, vinculados à Gerência de Políticas e Programas, sobre os quais o apoio atuaria visando a uma mudança do modelo de gestão.

A partir dos dois eixos de intervenção, foram criados dois subgrupos de apoio, com encontros mensais, para promover a intervenção: Grupo de Cogestão e Grupo de Apoio à Gerência de Políticas e Programas. A permanência do Colegiado Gestor do Recanto das Emas foi mantida, também com rodas de apoio mensais, como um espaço de formação e supervisão para os apoiadores compartilharem e analisarem seus processos de trabalho desenvolvidos nos dois subgrupos, ao mesmo tempo em que eram provocados a refletirem sobre o exercício do apoio institucional.

\section{Espaços de intervenção do apoio: Grupo de Cogestão}

Em julho de 2013, o Grupo de Cogestão realizou a sua primeira roda de apoio para a construção da matriz de intervenção do apoio. Nessa ocasião, algumas propostas foram discutidas: apoiar individualmente cada equipe; formar 
Figura 2

Problemas organizacionais identificados pelo Colegiado Gestor do Recanto das Emas.

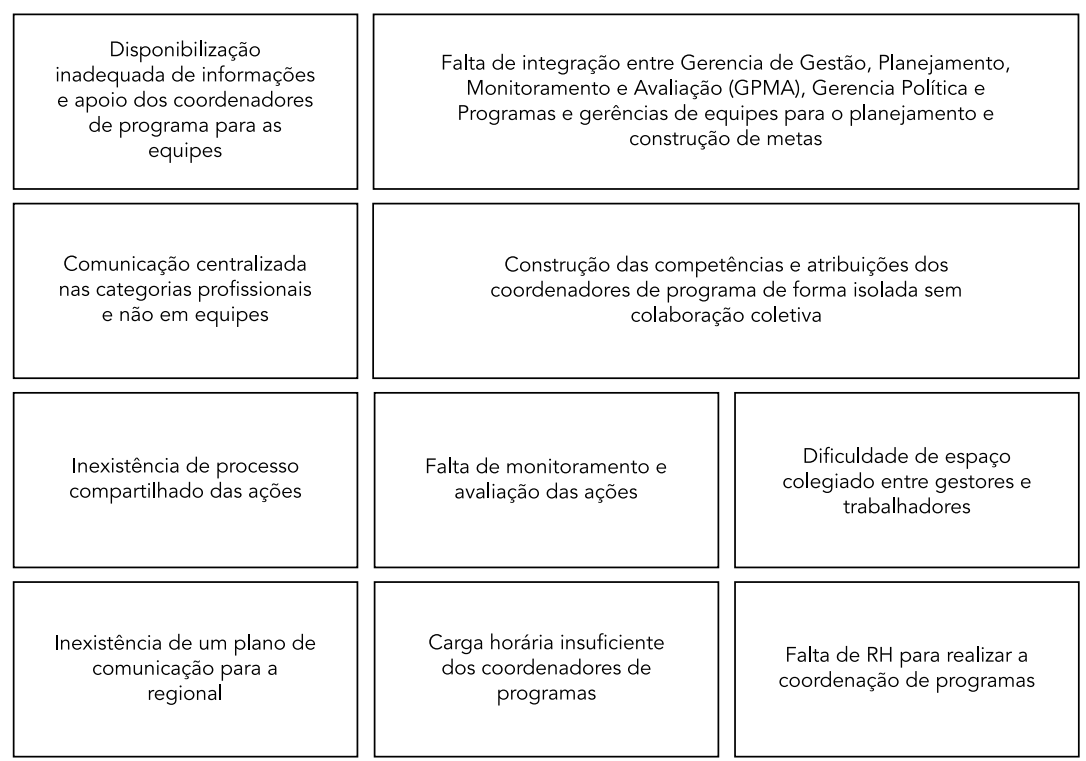

$\mathrm{RH}$ : recursos humanos.

colegiados em todas as unidades de saúde da regional; ou intervir em uma única unidade de saúde. Por consenso, definiu-se que as atividades de apoio seriam iniciadas em uma unidade de saúde com o propósito de gerar experiência, permitindo que os outros gerentes construíssem um colegiado de cogestão nas suas unidades de saúde a partir desse aprendizado. A Clínica da Família 1 foi a unidade escolhida em função de ter sido a primeira unidade a alocar sete equipes de saúde da família sem a devida capacitação e estruturação para seu funcionamento, de acordo com as diretrizes propostas pela PNAB. Apesar da Clínica da Família 1 ter um espaço para reuniões dos profissionais, eles não conseguiam realizá-las de forma sistemática e efetiva. O grupo elegeu o colegiado de cogestão de apoio como espaço de encontro dos profissionais, pois entendeu que era preciso ativá-lo.

A primeira roda do grupo de apoio à cogestão com os profissionais da Clínica da Família 1 foi realizada em agosto de 2013, para a qual foram convidados todos profissionais das equipes, incluindo-se pessoas que trabalhavam com serviços gerais. Nessa roda, foi apresentada a proposta de construção do espaço colegiado, com periodicidade mensal e com representantes de cada equipe, com equilíbrio de representação de todas as classes profissionais. Após a roda, o grupo de apoio à cogestão concluiu que o encontro foi tenso, e, apesar de não estarem previstas ocorrências de determinados embates, ele serviu de aprendizado para o processo de formação do exercício do apoio institucional.

O segundo encontro do colegiado da Clínica da Família 1 ocorreu em novembro de 2013 e teve, como tema, a matriz de problemas que eles haviam construído no início de 2013. Os profissionais dividiram os problemas entre: de gestão e de estrutura; e, a partir daí, foi possível identificar avanços e resoluções desses problemas. Novos problemas foram pontuados e elencados como temas que precisavam ser discutidos, como, por exemplo, demanda espontânea e definição dos fluxos assistenciais.

Depois de dez meses da realização do primeiro colegiado de cogestão da Clínica da Família 1, foi realizado o grupo focal com os apoiadores que compunham o colegiado gestor do Recanto das Emas para, dentre outras coisas, analisar o processo realizado na Clínica da Família 1.

"Entendemos que a implementação dos grupos de cogestão nas unidades básicas de saúde está sendo difícil porque, no momento, priorizamos 
a organização dos processos de trabalho das equipes. Nesse sentido, nossa proposta é ter mais pessoas discutindo as atividades diárias com as equipes contribuindo, de forma mais direta, para a melhoria da assistência e da gestão. Nós entendemos que, com o avançar dessas discussões, as equipes vão sentir a necessidade de pactuar suas ações e conversar sobre elas em um espaço de cogestão, pois essa organização é fundamental" (narrativa Colegiado Gestor do Recanto das Emas).

Nesse processo coletivo de construção, intervenção e avaliação das ofertas e das demandas dos coletivos, foi feita uma avaliação de que era preciso rever a estratégia de priorização da Clínica da Família 1.

"A estratégia da priorização da Clínica da Família 1 para implantação do colegiado de cogestão não foi boa porque nem todos os gerentes conseguiram realizar a implementação do colegiado nas demais unidades básicas de saúde, e o grupo de apoio à gestão focou as discussões na Clínica da Família 1, gerando um vazio de discussões com relação aos processos de trabalho das outras unidades de saúde. Um de nós traz a proposta de dividir os apoiadores em duplas para participarem e ajudarem na implementação dos colegiados nas outras unidades de saúde" (narrativa Colegiado Gestor do Recanto das Emas).

As mudanças nas práticas de gestão aconteceram mesmo sem a institucionalização dos colegiados.

"Concordamos que houve mudanças no processo de trabalho em função do apoio e, para um de nós, é visível a mudança do modelo de gestão, pois hoje a nossa gestão é participativa, todos são responsabilizados e temos espaços coletivos deliberativos. O gestor tem a responsabilidade neste processo, mas o apoio foi o precursor da mudança do modo de conduzir a gestão. Na opinião de alguns, ocorreram mudanças com relação à postura que era autoritária e verticalizada perante as equipes de saúde, e hoje buscamos compartilhar as responsabilidades com todos os profissionais, ampliamos nossos espaços de discussões e pedimos aos profissionais que tragam as sugestões para os problemas apontados" (narrativa Colegiado Gestor do Recanto das Emas).

As mudanças da gestão e das práticas profissionais modificaram também os sujeitos e os padrões dominantes da subjetividade, e, para esses movimentos construídos, foi possível perceber que as mudanças possibilitaram a coprodução de autonomia, ampliação da capacidade de análise e de cogestão das pessoas ${ }^{6}$.
Espaços de intervenção do apoio: Grupo de Apoio à Gerência de Políticas e Programas

O Grupo de Apoio à Gerência de Políticas e Programas realizou dois encontros, em julho e agosto de 2013, para planejar a primeira roda de apoio com os coordenadores de programas. De agosto de 2013 a fevereiro de 2014, foram realizadas cinco rodas de apoio com os coordenadores de programas, com o propósito de se repensar os processos de trabalho.

Em agosto de 2013, foi realizada a primeira roda de apoio com o objetivo de conhecer e entender como os coordenadores de programas se organizavam no Recanto das Emas.

“Não sabemos o que a Gerência de Políticas e Programas espera do nosso trabalho por não existir objetivos concretos, temos dúvidas de como conduzir as ações. Trabalhamos com temas específicos e não conseguimos atender as 23 ESF na carga horária disponível e, com isso, íamos para as equipes quando era possível e falávamos de coisas consideradas irrelevantes para elas, mas que eram necessárias para prestar conta para as nossas chefias" (narrativa do Grupo de Coordenadores de Programas).

Nesse encontro, a Gerência de Políticas e Programas não foi reconhecida como unidade gestora de referência e não havia um espaço de encontro para compartilhamento de atividades e agendas.

"Precisamos construir espaços de conversas para integrarmos nosso trabalho, para compartilharmos nossas agendas, para não ficar cada dia uma pessoa diferente na unidade atrapalhando o profissional no seu atendimento. Porque se outro coordenador já vai à unidade e eu preciso apenas buscar tal dado, por que ele não pode fazer isso para mim?" (narrativa do Grupo de Coordenadores de programas).

Na segunda roda de apoio, realizada em outubro de 2013, o Grupo de Apoio à Gerência de Políticas e Programas preparou uma dinâmica que pudesse problematizar e promover reflexões sobre a integralidade do cuidado, e, diante dessas reflexões, os temas apoio institucional e apoio matricial foram inseridos na discussão.

“Precisamos sair das 'caixinhas' e trabalharmos integrados porque não temos como continuar trabalhando com uma temática específica se as outras temáticas são transversais para a produção do cuidado, mas também é papel do coordenador, em alguns momentos, discutir algumas especificidades para que possam ajudar as ESF" (narrativa do grupo coordenadores de programas).

Na roda de apoio de fevereiro de 2014, após sete meses de encontros do Colegiado dos 
Coordenadores de Programas e depois da discussão do tema produção do cuidado, foi problematizada a reorganização do trabalho da Gerência de Políticas e Programas, com a constituição de apoiadores institucionais que fariam apoio para um número específico de ESF conforme proposto pelo Colegiado Gestor do Recanto das Emas e, ao mesmo tempo, continuariam sendo referência para as áreas temáticas, compartilhando o saber com os outros apoiadores e, em casos específicos, realizando o apoio matricial. Nos encontros semanais do Colegiado dos Coordenadores de Programas, ocorridos no mês de abril de 2014, o grupo compreendeu o papel do apoiador e reorganizou a Gerência de Políticas e Programas em Unidade de Produção que, de acordo com Campos 28 (p. 865), “[...] um novo modelo de fazer gestão em que todos os profissionais envolvidos com um mesmo tipo de trabalho, com um determinado produto ou objetivo identificável, passariam a compor uma Unidade de Produção, ou seja, cada um desses novos departamentos ou serviços seria composto por uma Equipe multiprofissional [...]".

A nova conformação da Gerência de Políticas e Programas ficou organizada com uma coordenadora e oito apoiadores, que ganharam a denominação de "assessores técnicos", sendo constituída dos seguintes profissionais: quatro médicos, dois enfermeiros, um dentista e um agente comunitário de saúde. O Recanto das Emas estava com 23 ESF, e o número de equipes para cada assessor técnico foi definido de acordo com a disponibilidade de carga horária para exercerem essa função. A escolha de qual equipe ficaria com qual assessor técnico foi determinada pelo coletivo, fazendo-se análise do contexto de cada equipe, levando-se, em conta, sua organização, seu processo de trabalho e envolvimento do gerente com a equipe.

Nas rodas de apoio do Colegiado dos Coordenadores de Programa, foram mapeadas as ESF que não realizavam as reuniões de equipe, $\mathrm{e}$ foram iniciados movimentos de conversas com os profissionais e com os gerentes para apoiar a implantação dessas reuniões. Essas se tornaram o espaço de inserção do assessor técnico no território das ESF. Depois de sete meses, o grupo trouxe algumas reflexões, avaliações e resultados: “Avaliamos que nossos objetivos estão sendo alcançados, tais como a institucionalização das reuniões de equipe, a receptividade com relação à nossa presença nas reuniões das equipes, o fortalecimento das reuniões de equipes existentes e a percepção dos profissionais sobre o trabalho compartilhado da gestão e da assistência. Algumas equipes já estão conseguindo ampliar as ofertas assistenciais" (narrativa Colegiado de Coordenadores de Programas).

A reorganização dos processos de trabalho dos coordenadores de programas conseguiu desconstruir processos instituídos e parte da cultura institucional verticalizada, o que confirma Campos 6 (p. 12): “Quando se descontrói algo, põe-se algo no lugar ainda que não de maneira explíci$t a$ " . Esse algo que foi colocado no lugar do antigo trouxe reflexões com relação à constituição dos sujeitos e da democracia organizacional que "todo pensamento comprometido com algum tipo de prática (política, clínica, sanitária, profissional) está obrigado a reconstruir depois de desconstruir. Sendo a saúde um campo comprometido com a prática" 6 (p. 11), o plano interventivo foi fundamental nesses processos de mudança.

\section{As prioridades da gestão e o apoio institucional}

Pela análise de informações e documentos construídos pelo grupo dirigente para inclusão de metas e prioridades do Recanto das Emas no Plano Distrital de Saúde 2012 a $2015^{3}$ do Distrito Federal, ocorrida nas rodas de apoio, verificou-se que os mesmos não foram considerados pelos gestores e nem pelos coordenadores de programa para elaboração de planejamento de suas ações, mesmo tendo participado de discussões de temáticas específicas durante a construção do plano de saúde, no âmbito do Recanto das Emas. Os problemas evidenciados nesses instrumentos de gestão foram os mesmos problematizados pelos gestores e coordenadores nas rodas de apoio, que também identificaram a necessidade de organizar as redes de atenção para além da Atenção Primária. Além disso, os planos não apresentam, com clareza, as ações a serem promovidas para o alcance das prioridades apresentadas no eixo da gestão.

Com a proposta do apoio institucional, os gestores buscaram implementar um novo modelo de gestão com a criação de espaços colegiados para possibilitar a ampliação da capacidade de análise e de ação cogestiva.

"Os encontros do grupo de apoio têm nos estimulado a refletir sobre formas de melhorar as práticas de gestão, na medida em que é melhor ter várias competências trabalhando juntas do que isoladamente. A participação dos chefes está sendo fundamental para se fazer uma gestão democrática e participativa, além de empoderar os demais participantes, pois, quando a gestão trabalha de cima para baixo e você não dá oportunidade para o trabalhador se sentar com a gestão e compartilhar as dificuldades, eles se sentem muito sozinhos, desamparados, soltos e 
excluídos. Quando se trabalha nessa perspectiva (apoio), as pessoas acabam se sentindo mais próximas, acolhidas, e isso faz total diferença para dar encaminhamento às coisas. Criamos vínculo com as pessoas, nos tornamos mais fortalecidos, $e$ todos se sentem corresponsáveis. Quando a gestão e a assistência trabalham juntas, há uma concordância que o outro também sabe fazer" (narrativa Colegiado Gestor do Recanto das Emas).

Pelas entrevistas com gestores da Subsecretaria de Atenção Primária à Saúde e da Coordenação Geral de Saúde do Recanto das Emas, foi possível identificar convergências das suas percepções de prioridade para a Atenção Primária com as prioridades descritas nos planos de saúde do Distrito Federal e do Recanto das Emas: o aumento da cobertura ESF como importante fator para o fortalecimento e a qualificação dos profissionais para trabalharem com a complexidade da Atenção Primária.

Para os assessores técnicos, as prioridades da Atenção Primária para o Recanto das Emas decorrem das demandas apresentadas pelas equipes e das ofertas apresentadas pelos gestores. Isso, sob o ponto de vista da cogestão, é um indicativo de que o coletivo está operando sobre a realidade na busca de sentido e significado, incorporando as vivências cotidianas dos processos de trabalho 16 .

“Entendemos que a Atenção Primária é primordial e que a proposta política é migrar do modelo tradicional, baseado em centro de saúde, para ESF. Para nós, a prioridade para a Atenção Primária está sendo a mortalidade materna e infantil que foi um tema que a gestão do Recanto das Emas apresentou para nós como prioritária, antes mesmo de iniciarmos as idas às equipes. Analisando os indicadores de saúde, entendemos como sendo prioridade também a hipertensão $e$ o diabetes, apesar de não gerar angústias às equipes como ocorre com o tema saúde mental, que faz com que as equipes se sintam paralisadas, sem saber como trabalhar com essa temática" (narrativa Colegiado de Coordenadores de Programas).

Apesar das convergências de algumas ações presentes nos planos de saúde, os gestores e profissionais não os utilizam como métodos de gestão, seja por motivos políticos, organizacionais ou circunstanciais. Os planos poderiam ser instrumentos facilitadores para os processos de priorização e de tomada de decisões de forma convergente e coesa no âmbito da assistência e da gestão de saúde do território. Entretanto, o apoio institucional, com a institucionalidade dos espaços de cogestão, tem propiciado o processo de qualificação das ações institucionais de gestão.
Devolutiva da pesquisa: oportunizando validação de categorias de análise e efetivando os processos participativos junto aos sujeitos interessados

A avaliação constante e permanente da pesquisa buscou compartilhamento das experiências vivenciadas e dos materiais produzidos em grupos focais e narrativas do processo, oportunizando a validação de categorias de análise no que se refere à incorporação das práticas de apoio, sua institucionalidade e institucionalização, para a constituição de novas formas de organização da gestão, efetivando os processos participativos junto aos sujeitos interessados.

No encontro final de avaliação, foram problematizadas três questões para os participantes: a primeira: "onde me vejo apoiando ou sendo apoiado?", a segunda: “em que espaços de trabalho/gestão vejo as práticas de apoio acontecendo?" e a terceira: "que indicativos de efeitos ou resultados você identifica como relacionados à incorporação das práticas de apoio no trabalho e na gestão?". Os participantes registraram suas percepções e experiências em tarjetas que foram agrupadas por similaridade de ideias e dispostas em um mural de forma organizada.

Foram constituídos os seguintes espaços de intervenção no Recanto das Emas a partir das práticas de apoio: Colegiado Gestor do Recanto das Emas, Colegiado da Diretoria Regional de Atenção Primária à Saúde, Colegiado dos Coordenadores de Programas, Colegiado da Clínica da Família 1, Colegiado do Centro de Saúde 2, Reuniões das Equipes e Colegiado dos Coordenadores das ESF; nos quais o apoio vem sendo exercido pelos apoiadores da Subsecretaria de Atenção Primária em Saúde, apoiadores da Regional de Saúde do Recanto das Emas, alunos da graduação e pós-graduação e professores da UnB, além de professores da Fiocruz.

A incorporação das práticas de apoio no trabalho e na gestão na Regional de Saúde do Recanto das Emas proporcionou a conversão da Gerência de Políticas e Programas em Unidade de Produção 28, mudança da forma de apoio do Comitê de Óbito Materno Infantil às ESF e a construção, o fortalecimento e a qualificação de espaços coletivos recém construídos e preexistentes, tornando-os espaços de cogestão. Esses movimentos não foram identificados na estrutura da Subsecretarias de Atenção Primária em Saúde nem na FEPECS. Para a UnB, serviu de parâmetro para mudanças significativas nas relações da universidade com o SUS do Distrito Federal pela inserção dos alunos de graduação e pós graduação como apoiadores, sustentados por uma relação de contrato ético entre a universidade e o SUS. 


\section{Considerações finais}

Concluímos que a experimentação do apoio propiciou: mudança no cotidiano dos processos de trabalho; humanização e melhoria das relações de trabalho; implantação de colegiados gestores; ativação de redes de coletivos preocupados com a qualificação da assistência e da gestão; mudança do modelo de atenção e de gestão e de seus processos de trabalho sem distanciamento das suas atividades; intervenção nas práticas cotidianas dos serviços da Atenção Primária; perturbação de tendências tecnocráticas autoritárias e apropriação das práticas de gestão pelos trabalhadores.

\section{Colaboradores}

J. R. Cardoso participou da concepção, projeto, análise e interpretação dos dados, redação do artigo, revisão crítica relevante do conteúdo intelectual e foi responsável por todos os aspectos do trabalho na garantia da exatidão e da integridade de qualquer parte da obra. G. N. Oliveira e P. G. Furlan participaram da concepção, projeto, redação do artigo, revisão crítica relevante do conteúdo intelectual e aprovação da versão a ser publicada.
O objetivo de cartografar as práticas de apoio da Subsecretaria de Atenção primária em Saúde e da Diretoria Regional de Atenção Primária à Saúde e correlacioná-las com as prioridades da gestão do SUS do Distrito Federal foi alcançado, entretanto, este trabalho não está encerrado e ambiciona um movimento instituinte no qual o conhecimento seja operado e produzido pelo coletivo de trabalhadores e pesquisadores na perspectiva da ética democrática, com a pesquisa acadêmica promovendo intervenção nos processos de produção da realidade em que ela se instala.

\section{Agradecimentos}

Aos gestores e trabalhadores da Subsecretaria de Atenção Primária à Saúde, Distrito Federal e da Regional de Saúde do Recanto das Emas, Distrito Federal, pela construção deste trabalho e do SUS. Aos pesquisadores da Fundação Oswaldo Cruz e aos alunos de graduação da UnB pelo apoio ao longo de toda a pesquisa. A Eder Luiz Menezes de Faria pelas contribuições com a edição, a revisão e a diagramação deste trabalho. 


\section{Referências}

1. Hildebrand SM. O modelo político-tecnológico da atenção à saúde da família no Distrito Federal: 1997 a 2006 [Tese de Doutorado]. Brasília: Faculdade de Ciências da Saúde, Universidade de Brasília; 2008.

2. Distrito Federal. Decreto no 32.104 , de 24 de agosto de 2010. Extingue e cria cargos que especifica e dá outras providências. http://www.buriti.df.gov. br/ftp/diariooficial/2010/08_Agosto/DODF\%20 164\%2025-08-2010/Se\%C3\%A7\%C3\%A3o01-\%20 164.pdf (acessado em 09/Jun/2013).

3. Secretaria de Estado da Saúde do Distrito Federal. Plano Distrital de Saúde 2012 a 2015. http:/ /www. saude.df.gov.br/images/Conselho\%20de\%20Sau de\%20do\%20DF/planodesaude_2012_2015\%201. pdf (acessado em 08/Jun/2013).

4. Cardoso IM. "Rodas de Educação Permanente" na Atenção Básica de Saúde: analisando contribuições. Saúde Soc 2012; 21 Suppl 1:18-28.

5. Oliveira GN. Devir apoiador: uma cartografia da função apoio [Tese de Doutorado]. Campinas: Faculdade de Ciências Médicas, Universidade Estadual de Campinas; 2011.

6. Campos GWS. Saúde Paidéia. 3a Ed. São Paulo: Editora Hucitec; 2007.

7. Andrade MC, Castanheira ERL. Cooperação e apoio técnico entre estado e municípios: a experiência do Programa Articuladores da Atenção Básica em São Paulo. Saúde Soc 2011; 20:980-90.

8. Barros SC, Dimenstein M. O apoio institucional como dispositivo de reordenamento dos processos de trabalho na atenção básica. Estud Pesqui Psicol 2010; 10:48-67.

9. Arona EC. Implantação do matriciamento nos serviços de saúde de Capivari. Saúde Soc 2009; 18 Suppl 1:26-36.

10. Moura RH, Luzio CA. O apoio institucional como uma das faces da função apoio no Núcleo de Apoio à Saúde da Família (NASF): para além das diretrizes. Interface Comun Saúde Educ 2014; 18 Suppl 1:973-86.

11. Becchi AC, Albiero ALM, Pavão FO, Pinto IS, Godoi AV, Dias BC, et al. Perspectivas atuais de cogestão em saúde: vivências do Grupo de Trabalho de Humanização na Atenção Primária à Saúde. Saúde Soc 2013; 22:653-60.

12. Vasconcelos MFF, Morschel A. O apoio institucional e a produção de redes: do desassossego dos mapas vigentes na Saúde Coletiva. Interface Comun Saúde Educ 2009; 13 Suppl 1:729-38.

13. Barros MEB, Guedes CR, Roza MMR. O apoio institucional como método de análise-intervenção no âmbito das políticas públicas de saúde: a experiência em um hospital geral. Ciênc Saúde Coletiva 2011; 16:4803-14.

14. Ministério da Saúde. Portaria GM/MS no 2.488 de 21 de outubro de 2011. Aprova a Política Nacional de Atenção Básica, estabelecendo a revisão de diretrizes e normas para a organização da Atenção Básica, para a Estratégia Saúde da Família (ESF) e o Programa de Agentes Comunitários de Saúde (PACS). Diário Oficial da União 2001; 24 out.
15. Núcleo Técnico da Política Nacional de Humanização, Secretaria de Atenção à Saúde, Ministério da Saúde. HumanizaSUS: documento base para gestores e trabalhadores do SUS. 4a Ed. Brasília: Ministério da Saúde; 2008.

16. Campos GWS. Um método para análise e cogestão de coletivos. 2ạ Ed. São Paulo: Editora Hucitec; 2005.

17. Oliveira GN, Furlan PG, Cardoso JR. Pesquisaintervenção na atenção primária à saúde do Distrito Federal: o papel da universidade no apoio institucional para o desenvolvimento regional e a democratização do SUS. In: Pinheiro R, Silva FH, Lopes TC, Silva Júnior AG, organizadores. Práticas de apoio e a integralidade no SUS: por uma estratégia de rede multicêntrica de pesquisa. Rio de Janeiro: Centro de Estudos e Pesquisa em Saúde Coletiva, Instituto de Medicina Social, Universidade do Estado do Rio de Janeiro/ABRASCO; 2014. p. 281-306.

18. Baremblitt G. Compêndio de análise institucional e outras correntes. 5a Ed. Belo Horizonte: Instituto Félix Guattari; 2002.

19. Companhia de Planejamento do Distrito Federal. Pesquisa distrital por amostra de domicílios: Recanto das Emas. Brasília: Companhia de Planejamento do Distrito Federal/Secretaria de Estado de Planejamento e Orçamento do Distrito Federal; 2013.

20. L'abbate $\mathrm{S}$. A análise institucional e a saúde coletiva. Ciênc Saúde Coletiva 2003; 8:265-74.

21. Passos E, Barros RB. A cartografia como método de pesquisa-intervenção. In: Passos E, Kastrup V, Escóssia L, organizadores. Pistas do método da cartografia: pesquisa-intervenção e produção de subjetividade. Porto Alegre: Editora Sulina; 2009. p. 17-21.

22. Guba E, Lincoln Y. Avaliação de quarta geração. Campinas: Editora Unicamp; 2011.

23. Gadamer HG. Verdade e método. Petrópolis: Editora Vozes; 2008.

24. Deleuze G. Conversações, 1972-1990. São Paulo: Editora 34; 1992.

25. Figueiredo MD, Onocko Campos R. Saúde Mental na atenção básica à saúde de Campinas, SP: uma rede ou um emaranhado? Ciênc Saúde Coletiva 2009; 14:129-38.

26. Ricoeur P. Interpretação e ideologias. 4ạ Ed. Rio de Janeiro: Editora Francisco Alves; 1990.

27. Ricoeur P. Tempo e narrativa. São Paulo: WMF Martins Fontes; 2010.

28. Campos GWS. O anti-Taylor: sobre a invenção de um método para co-governar instituições de saúde produzindo liberdade e compromisso. Cad Saúde Pública 1998; 14:863-70. 


\section{Abstract}

The study was performed within the framework of the Brazilian Unified National Health System (SUS) in the Federal District, Brazil, focusing on the role of institutional support in reframing work and management practices in primary care. The study aimed to map practices for supporting primary care in the Recanto das Emas Regional Administration, correlated with the Federal District's health priorities. The study design included qualitative intervention research with participant methods and production of collective narratives. Testing the support provided qualification and alignment of institutional measures with management priorities, qualification, humanization, and improvement of work and management processes, collegiate decision-making, and intervention in daily practices in primary care services. The study concludes that support practices can enhance democratic management processes and contribute to improving care.

Primary Health Care; Integrality in Health; Health Management; Humanization of Assistance

\section{Resumen}

La investigación se ha llevado a cabo en el marco del Sistema Único de Salud brasileño en el Distrito Federal, apostando por la inserción de apoyo institucional, como dispositivo para replantear la comprensión de los procesos y la gestión en atención primaria. En este contexto, hemos tratado de trazar las prácticas de apoyo en la atención primaria de la salud de la administración regional de Recanto das Emas y correlacionarlas con las prioridades de salud del Distrito Federal, a través de la intervención de investigación en el marco cualitativo, con métodos participativos y narrativas de producción colectiva. Entre las prácticas de apoyo están presentes: cualificación y la alineación de las acciones institucionales con prioridades de gestión; calificación, humanización y la mejora de los procesos y la gestión de trabajo; implementación de administradores colegiados; intervención en las prácticas cotidianas de los servicios de atención primaria. De ello se desprende que las prácticas de apoyo pueden mejorar los procesos de gestión democrática y contribuir a la calidad de la asistencia.

Atención Primaria de Salud; Integralidad em Salud; Gestión em Salud; Humanización de la Atención 